\title{
Problems in Substation Equipment Maintenance and Repair
}

\author{
Yuan Dan \\ Dalian Power Supply Company, State Grid Liaoning Electric Power Supply Co., Ltd. \\ 22181221@qq.com
}

Keywords: Electrical Power System; Substation Equipment Maintenance and Repair; Problems; Countermeasures.

\begin{abstract}
Along with the rapid development in modern science and technology, the equipment in every manufacturing industry and field has been constantly renewed and upgraded. It is the same case with the equipment of power enterprises, which have been enhanced under the general background of scientific and technological development. However, along with the scientific and technological development and constant renewal of equipment, the model for electric power overhaul has not been improved. Such old operating mode can no longer meet the demands for power system overhaul, thus leading to the frequent failures in substation equipment maintenance and repair. This paper offers an analysis of the issues existing in substation equipment maintenance and repair and proposes the well-targeted counter-measures.
\end{abstract}

\section{Introduction}

Along with the constant development of socialist market economy, people's living standards have been substantially enhanced. Under such circumstances, people have greater demands for various electric appliances and power supply in their life. So as to comply with the development of times and people's demands, it is of prime importance to strengthen the maintenance, repair and management of electric power system. In the management of electric power system, substation equipment maintenance and repair is necessary and serves as the precondition for the safe and stable operation of state grid. However, in the actual work of substation equipment maintenance and repair, under the influence of multiple factors, issues in electric power overhaul keep popping up. To quickly find identify the issues in substation equipment maintenance and repair, rectify and reform and avoid major electric power security accidents, it is essential to strengthen the overhaul of substation equipment.

\section{Analysis of the Problems Existing in Substation Equipment Maintenance and Repair}

Since reform and opening up, the past 3 decades have seen the economic development in China. Scientific and technological development has enhanced the technology of substation equipment maintenance and repair. With the help of modern equipment, the scope of application of the relevant technology has been expanded, thus enhancing the efficiency and accuracy of substation equipment maintenance and repair. The application of modern computer technology and information technology to the technology of substation equipment maintenance and repair has realized data sharing, storage and processing of substation equipment maintenance and repair, enabling the staff of power enterprises to better utilize the data information in electrical power system. However, in actual application, there are still many problems.

\section{Problems Caused by External Factors}

The failures in substations are caused by factors of two aspects: one is the human factors and the other is environmental factors. For example, the staff of power enterprises all wear protection suit to prevent the damage of the direct contact with electric current to human body in electrocircuit examination. However, as such insulating protective clothing has prevented the tiny charges carried by the staff from being released and will bring potential security hazard to the substation enterprises. At the meantime, the electromagnetic radiation and microcurrent of the substation 
equipment will affect the normal operation. It is also worth-noticing that the changes in external environment will also bring substantial influence to substation maintenance.

\section{Simple Mode of Substation Equipment Maintenance and Repair}

As the technology for substation equipment maintenance and repair in power unit has been fully developed, the mode of substation equipment maintenance and repair does not change accordingly. For example, in some power enterprises, due to the influence and restriction of technology, capital and personnel factors, periodical maintenance and repair is still applied in substation equipment maintenance and repair. Such working mode has made the substation equipment maintenance and repair quite passive, thus failing to meet the demands for the development of power enterprises in the news times and seriously restricting the safe, efficient and scientific operation of power enterprises.

\section{Low Management Efficiency of Substation Equipment Maintenance and Repair}

For a long time, the power enterprises in China has been influenced by the planned economy and placed at the monopoly position. Along with the accelerated development pace of marketization of power enterprises, power enterprises should change their concepts as soon as possible, establish brand-new market economy concept, proactively participate in market competition and attach more importance to the increase in enterprise management level so as to embrace the new age. However, during the new period of social development, along with the complicated power system, the management level of power system has not been enhanced. The management of the substation equipment maintenance and repair, in particular, has become increasingly disorderly. For example, lack of scientific, improved and standardized management mode, many power enterprises do not have clear maintenance targets; many workers fail to lay stress on the maintenance and repair, or to timely identify the various potential security hazards in the operation of equipment. These unimproved management has given rise to the frequent problems and securities incidents.

\section{Low Technical Level of Maintenance Personnel}

Currently, most of the technicians of substation equipment maintenance and repair are directly engaged in the maintenance and repair works without receiving professional technical training or post safety training. For example, among the 8 personnel in the maintenance crew of some power enterprises, the number of newcomers even reaches 6 . Along with the deepening grid construction of power enterprises, the automated and integrated management has been applied to transformer substations; however, the maintenance and repair skills of the personnel cannot catch up with the upgrading pace of the equipment. It can be said with without solid specialized knowledge ,strengthened professional judgment competence or rich working experience, the rigor, scientific nature and stringency of substation equipment maintenance and repair will not be guaranteed. Besides, with the wide application of modern information technology, the transformer substation has been gradually intelligentized. Abundant operation requires the staff to familiarize themselves with computer knowledge and application. Therefore, the technical and professional qualities of the relevant personnel plays a vital role in advancing the development of power enterprises.

\section{Effective Countermeasures for the Increase in the Efficiency of Substation Equipment Maintenance and Repair}

The relatively sensitive electronic components might be susceptible to electromagnetic signals and environmental charges, a fact that results in equipment failure and safety hazards in daily operation. Therefore, the substation equipment maintenance and repair of power enterprises is of great significance. It is crucial to take effective maintenance and repair measures to prolong the service life of electric transducer and provide stable and safe power to the production and life of the general public.

The Application of Condition-based Maintenance Technology to Substation Equipment Maintenance and Repair

To avoid substation equipment failure caused by human factors or environmental factors in maintenance and repair, it is demanding to take the substation state maintenance and repair 
technologies, which fully adopt various real-time status detection technology so as to analyze and compare the limiting protection device. This technology guarantees the normal operation of power supply unit while ensuring the timely finding of equipment failure and enables the staff to gain an effective mastery over the future development trend of transformer equipment.

\section{Improve the Maintenance and Repair Mode}

In the process of the constant development of electricity utility in China, the improved substation equipment maintenance and repair could effectively reduce the operating cost of power enterprise. However, the lagged maintenance and repair mode in the actual work has severely influenced the enhancement of the overall level of maintenance and repair, thus increasing the related costs and operating cost of power enterprises, which is unfavorable to the healthy, stable and sustainable development of power enterprises. Under such circumstances, the power enterprises must fundamentally change the traditional substation equipment maintenance and repair mode should not make efforts at the last moment. The power enterprises should proceed from the actual conditions of enterprises and adopt advanced maintenance and repair technologies, methods and overhaul beforehand cases so as to enable the staff to find various hidden safety hazards and guarantee the normal operation of electrical power system.

\section{Strengthen the Enhancement of the Management Level of Substation Equipment Maintenance and Repair}

It requires the power enterprises to adopt scientific, rational and standardized management methods according to their actual conditions in maintenance and repair work management so as to ensure the scientific, standardized, informationalized and modernized development. For example, the power enterprises must be clear of the main targets of substation equipment maintenance and complete the substation equipment maintenance and repair under the guidance of the target; record the maintenance work so as to lay foundation for the future maintenance and management of equipment; improve each management system, establish and perfect the incentive and performance assessment system and ask each employee to undertake their tasks so as to effectively advance the vigorous development of substation equipment maintenance and repair.

\section{Enhance the Comprehensive Quality of Staff of Substation Equipment Maintenance and Repair}

Along with the constant development of power enterprises, higher requirements have been raised for the maintenance and repair workers. The maintenance and repair workers are asked to master excellent mastery of professional technical expertise and familiarize themselves with the application of modern information and computer technology. At the meantime, the maintenance and repair workers must also be possessed of noble quality of professional ethics. For example, power enterprises can offer periodical professional skill training to the relevant personnel so as to enhance the comprehensive qualities and ensure the successful implementation of substation equipment maintenance and repair with personnel guarantee.

In general, as an indispensable and important work in electrical power system, substation equipment maintenance and repair plays an important role in promoting the healthy, stable and sustainable development of power system. Therefore, it is of prime importance to strengthen the management level and working efficiency from different perspectives and lay solid foundation for the development of electricity utility.

\section{References}

[1] Ou Zhirong. On the Problems in Substation Equipment Maintenance and Repair of Power Supply Companies and the Measures [J]. Technology and Market, 2013 (08).

[2] Wei Sile. The Problems in Substation Equipment Maintenance and Repair and Countermeasures [J]. China High Technology Enterprises, 2014 (03).

[3] Li Zibin. On the Problems in Substation Equipment Maintenance and Repair and Measures [J].Chinese E-Commerce, 2014 (05). 
[4] Guo Jing, Ma Zhiying, Lei Qing. Optimizing deign of Cam Mechanism in Spring Operating Mechanism of Vacuum Circuit Breaker II. High-voltage electrical appliances, 2004,40 (3): 420-423.

[5] Lu Jizhi. On the Condition-based Maintenance and Development of Electric Transmission and Transformation Equipment[J ].Yunan Electric Power.

[6] Ma Jie. Carry out Equipment Condition-based Maintenance and Ensure the Safe Operation of Power Grid[J].Sci-Tech Information Development \& Economy. 